\title{
O PROCESSO DE REQUALIFICAÇÃo URBANA EM ASSAÍ-PR
}

\author{
HUMBERTOYAMAKI ${ }^{1}$ \\ MILENA KANASHIRO ${ }^{2}$ \\ FAUSTO ANAMI ${ }^{3}$
}

YAMAKI, K; KANASHIRO, M.; ANAMI, F. O processo de requalificação urbana em Assaí-PR. Semina: Ci. Exatas/Tecnológicas, Londrina, v. 16, n. 4, p. 581-590, dez. 1995.

RESUMO: Assai, ex-Colônia Três Barras, localizada no Norte do Paraná, foi fundada em 1932 pela Sociedade Colonizadora do Brasil-BRATAC, visando principalmente o assentamento de imigrantes japoneses. Planejado, o núcleo urbano manteve no plano inicial características morfológicas persistentes de projetos de Companhias de Colonização. Em 1993 iniciou-se um processo de estruturação da cidade visando a recuperação do caráter local e da identidade, a REQUALIFICAÇÃO URBANA, objeto desta comunicação. A análise tipo-morfológica e o inventário do conjunto visando a definição e apreensão de suas características fundamentais levou à redescoberta de um estoque de construções coesas e significativas. Tal fato reafirma a necessidade de uma continuidade, um potencial de atratividade. À fragilidade das construções em madeira aliada ao lento desaparecimento das técnicas construtivas e ao pouco reconhecimento, o que resta da arquitetura assaiense vem sendo lenta e sistematicamente erodida. Duas vertentes com legislação adequada de incentivo são propostas: 1. inventário e definição de características fundamentais de conjunto; 2. a manutenção possível do acervo tradicional e a "criação" de uma nova tradição baseada em regulamentação fortalecendo a regionalidade. Defender e criar uma paisagem para ser vivida e vista pressupõe a ação de despertara comunidade à valorização da experiência do lugar.

KEYWORDS: Requalifícação urbana; morfologia; inventário de conjunto.

\section{INTRODUÇÃO}

Em 1993 iniciou-se em Assaí-PR, cidade imigrante planejada, um processo de reestruturação visando a recuperação do caráter local e da identidade e sua transformação em potencial de atratividade.

Como referências necessárias foram consideradas entre outras: a experiência ingiesa de Essex (GB) com seu Design Guide, Blumenau (SC) e o incentivo às construções tradicionais e Itá (SC) como Cidade Nova incorporando elementos culturais tradicionais.

O processo chamado Requalificação Urbana procura desenvolver nesta cidade de 13000 habitantes, um trabalho em duas vertentes básicas:

1) inventário do conjunto visando a definição e apreensão de suas características fundamentais;

2) a manutenção do acervo tradicional e a criação de uma nova tradição através da análise tipo-morfológica.

Paralelamente, têm-se ampliado mecanismos para a participação efetiva da comunidade para que se possa criar uma nova relação, perspectiva de novo processo.

\section{HISTÓRICO}

Assai, ex-Colónia Três Barras foi fundada em 1932 pela Sociedade Colonizadora do Brasil-BRATAC, na região Norte do Paraná visando principalmente 0 assentamento de imigrantes japoneses.

A BRATAC vinha desenvolvendo uma série de assentamentos, entre eles Bastos e Pereira Barreto (SP), onde procurava desenvolver simultaneamente, a área rural e a urbana suporte.

Assaí manteve no seu planejamento características morfológicas persistentes de projetos de Companhias de Colonização Japonesa. Na área rural, a subdivisão em seções módulo tendo a Escola e o Kaikan(Centro de Convivência)como núcleo. Na área urbana, o traçado é basicamente ortogonal com eixo estruturador central junto ao qual localizava-se estrategicamente como "core" a Escola e não a usual Igreja.

\section{PLANO DA CIDADE}

O plano inicial do núcleo urbano procura adaptar a

1 - Autor, Arquiteto, Prof. Adjunto Dr. DAU/CTU/UEL.

2 - Co-autor, Arquiteta, Prof. Auxiliar DAU/CTU/UEL, Mestranda UnB.

3 - Colaborador, Arquiteto, Prof. Auxiliar DAU/CTU/UEL.

Semina Ci. Exatas/Tecn., v. 16, n. 4, p. 581-590 
malha rígida praticada peta BRATAC em experiências anteriores num sítio característico: na encosta de um espigão estreito cercado de vales.

Um eixo principal e quadras regulares definem a estrutura idealizada. Necessária citação à estratégica localização da Escola junto à Avenida, contrapondo com a Igreja e Hospital. Na saída da cidade, o Cemitério.

Algumas ruas diagonais são propostas no projeto, mas nunca efetivadas. Certamente eram um recurso de sugerir uma dinâmica e embelezamento do piano, reforço na imagem urbana (Fig. 1).

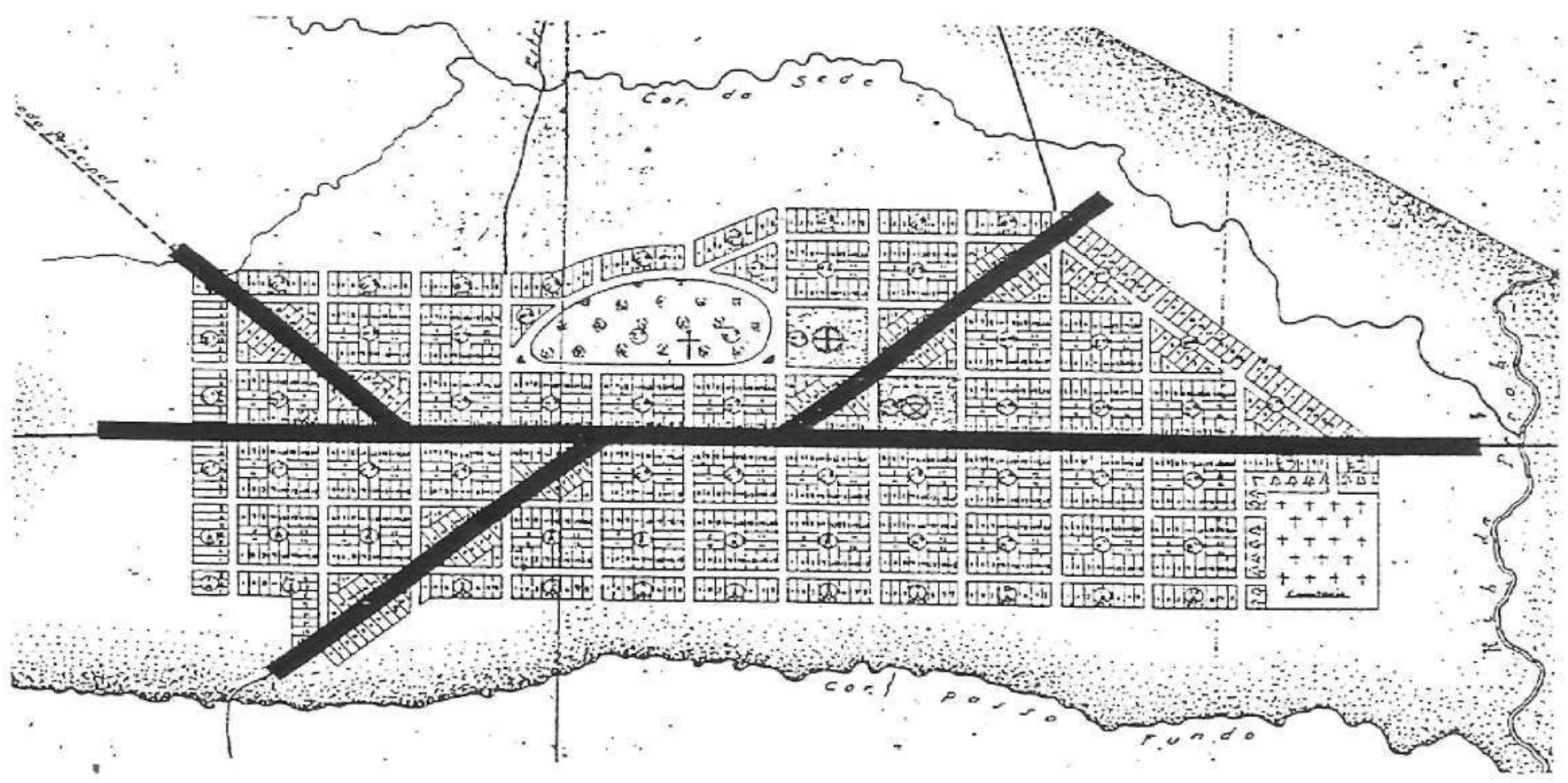

FIGURA 1 - Planta Inicial de Assai (1934)

\section{INCENTIVOS INICIAIS}

Visando o desenvolvimento do núcleo urbano já no início da colonização,a BRATAC doa lotes a comerciantes que se instalassem, bem como isenta das prestações do ano seguinte à construção de residências com área superior a $24 \mathrm{~m}^{2}$ em alvenaria de tijolos e cobertura de telhas de barro. Incentivos para 0 fortalecimento do núcleo urbano e a definição de uma nova paisagem.

\section{A qualidade das construções era outra}

preocupação da Companhia já no início do assentamento. A BRATAC organizava concursos de projetos sugerindo a criação de uma arquitetura adequada à nova realidade: econômica, salubre e com preocupações estéticas.

As várias propostas de elevações, planta-baixa e memorial mostram um processo evolutivo no solucionar a construção.As casas iniciais com nítidas referências nipônicas são logo substituídas por um tipo definindo as características locais (Fig. 2). 

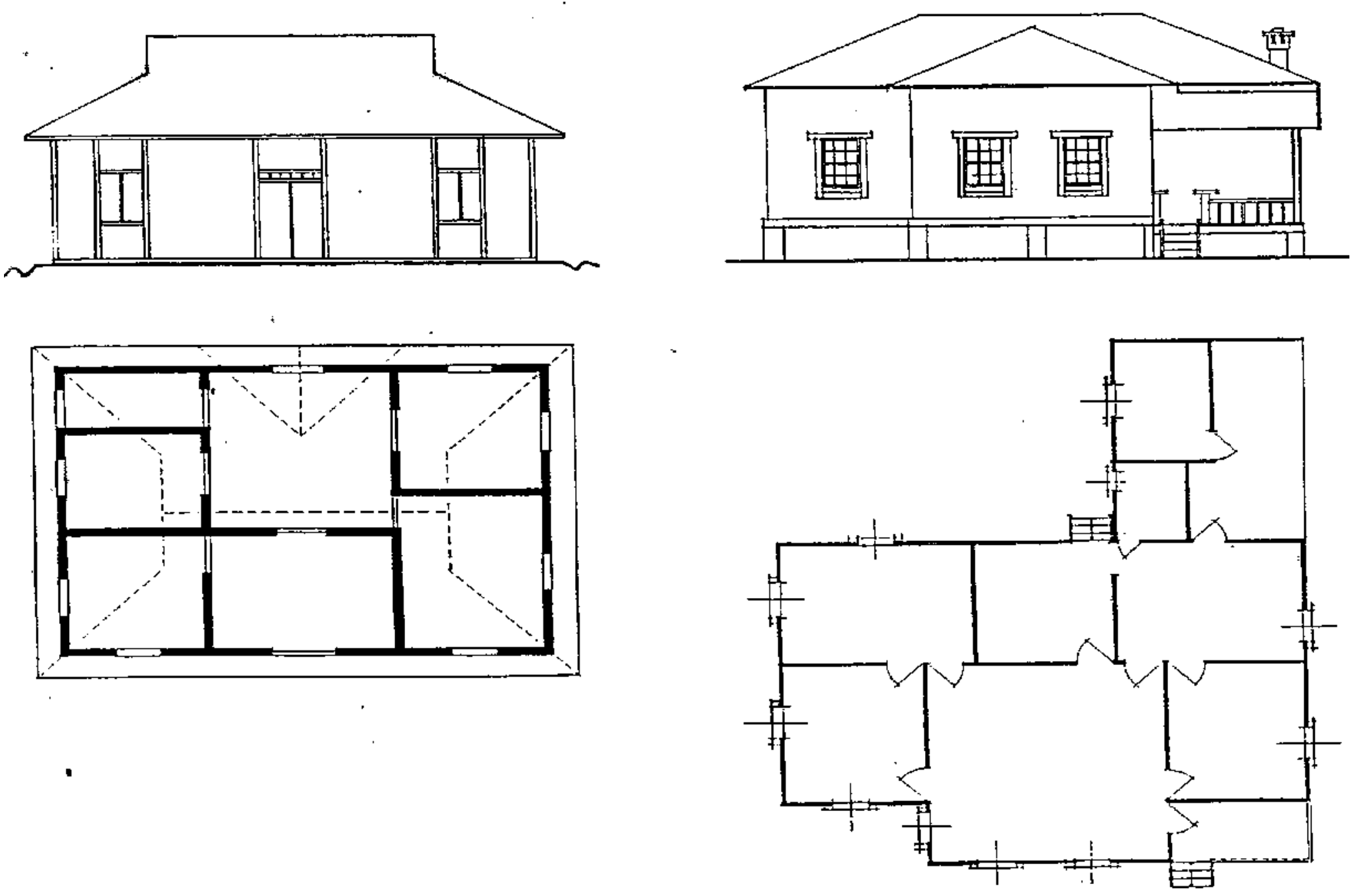

FIGURA 2 - Concurso BRATAC (Acervo do Museu Histórico da Imigrặăo Japonesa no Brasi] - SP)

\section{INVENTÁRIO}

O levantamento e a apreensão dos elementos de caracterização das unidades pré-definidas foram realizadas através de fichas de inventário que procuram detectar os elementos significativos na definição de unidade e conjunto/seqüência.
A cobertura e a sua articulação principalmente, e elementos suporte de caracterização como Ranma/ Lambrequim, Onigawara/Telha de Ponta, Guenkan/ Varanda constituem parte essencial do levantamento.

Em relação ã definição de conjunto, são considerados significativos, entre outros, a seqüência muro e sua adequação ao sítio, cor e material (Fig. 3). 

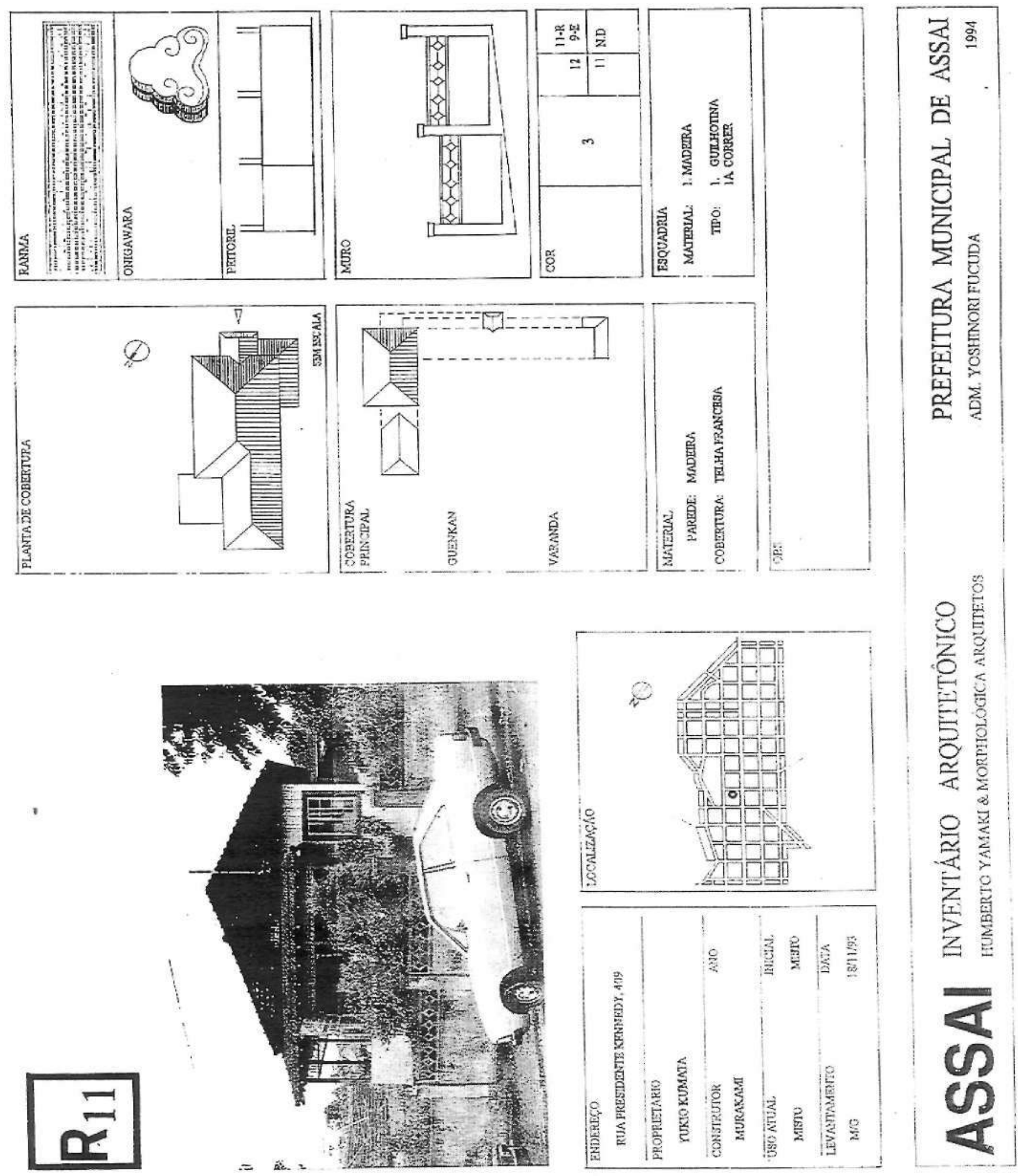

FIGURA 3 - Ficha de Inventário 


\section{ARQUITETURA ASSAIENSE}

A arquitetura tradicional de Assaí foi construída predominantemente pelos mestres carpinteiros japoneses-Daiku. Os mestres, vindos para a construção de edificações da Companhia, logo dedicavam-se às residências. Em determinada época trabalhavam na região mais de 16 mestres de níveis técnicos variados formando uma cooperativa (Fig. 4).

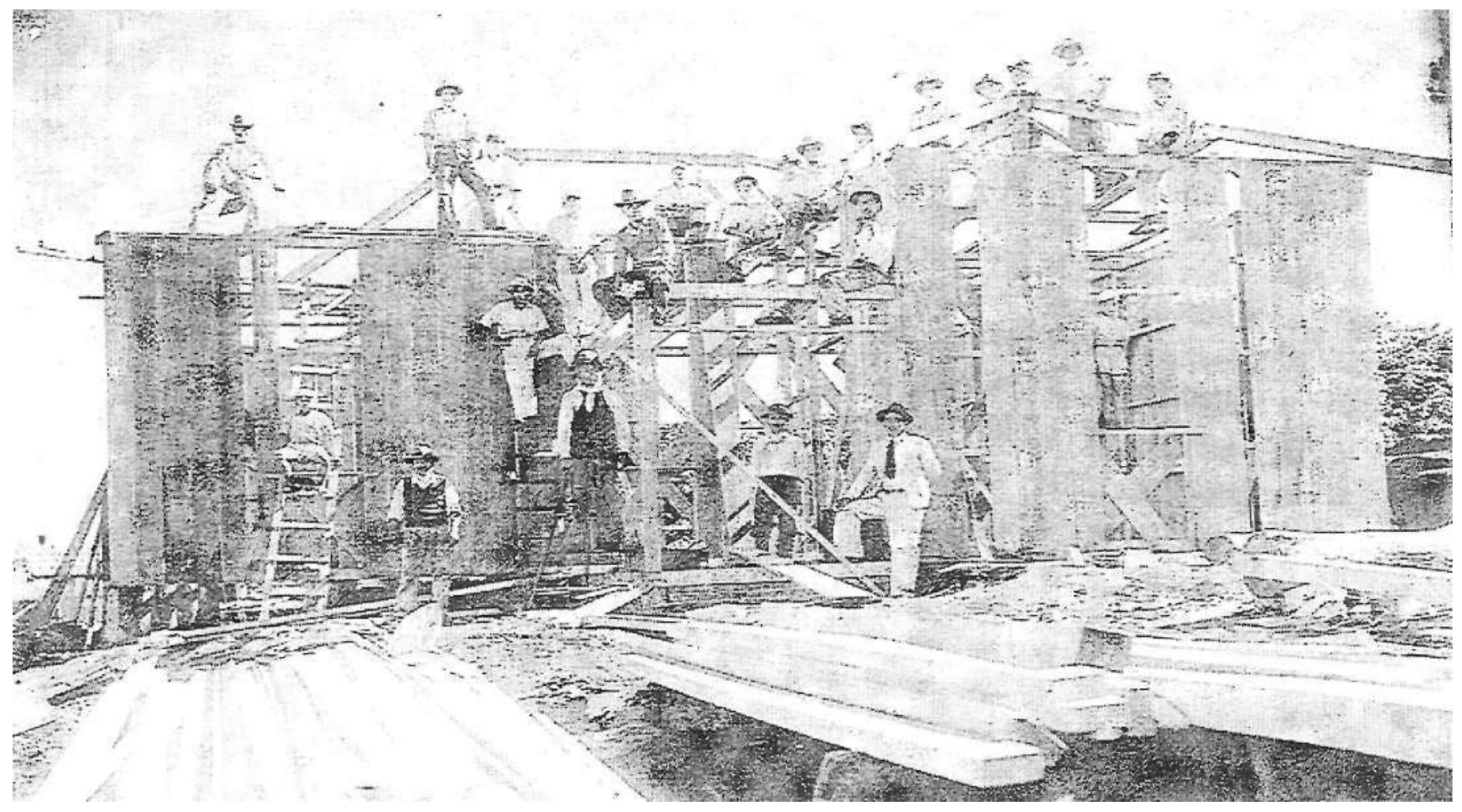

FIGURA 4 - Mestres-Carpinteiros - Daiku

A casa assaiense é carregado de traços nipônicos. Apesar da inegável influência, assume identidade própria através da incorporação de elementos indissociáveis à formação de uma tipologia. A arquitetura local difere fundamentalmente da arquitetura nipônica no fato de não se tirar o calçado para entrar no seu interior, característica essencial no Japão. Tal fato 
influencia desde a definição do espaço interior, a mobília ao uso dos espaços.

Em Assaí, há a exteriorização dos elementos nipônicos que se tornam signos, símbolo de uma arquitetura idealizada. A imponente cobertura tipo "irimoya" com forte inclinação, o "guenkan" e varanda, ornamentos como "onigawara" e "ranma" constituem elementos de identificação (Fig. 5).
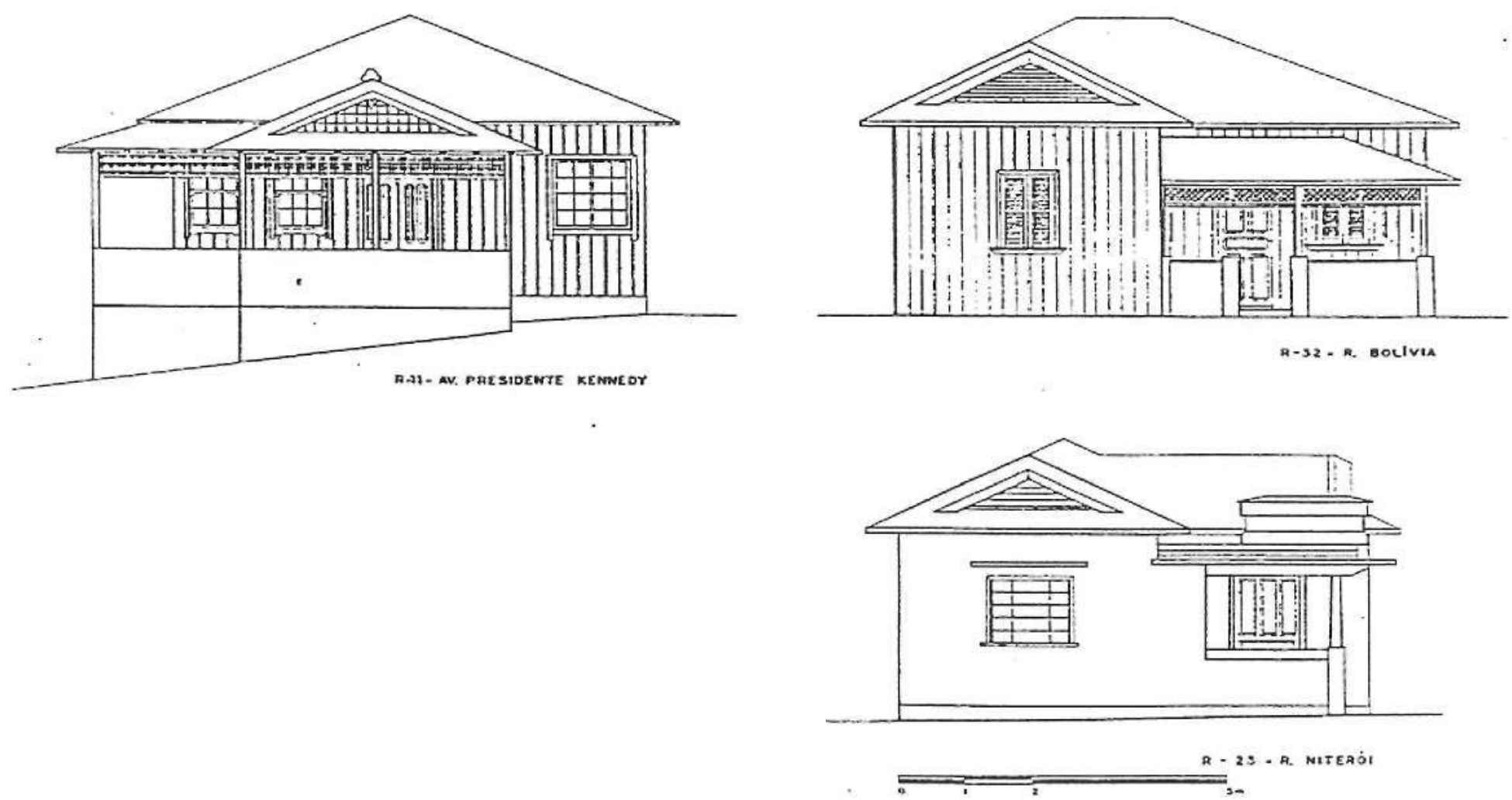

FIGURA 5 - Evolução dos Tipos-Padrão

Os detalhes dos ranmas são a marca visível e particular de cada Daiku.

Os quatro tipos básicos de cobertura: Irimoya,
Piramidal, Quatro Águas com Cumeeira Estreita, Quatro Águas e suas articulações apresentam grande variedade de resolução \{Figs. 6/7). 

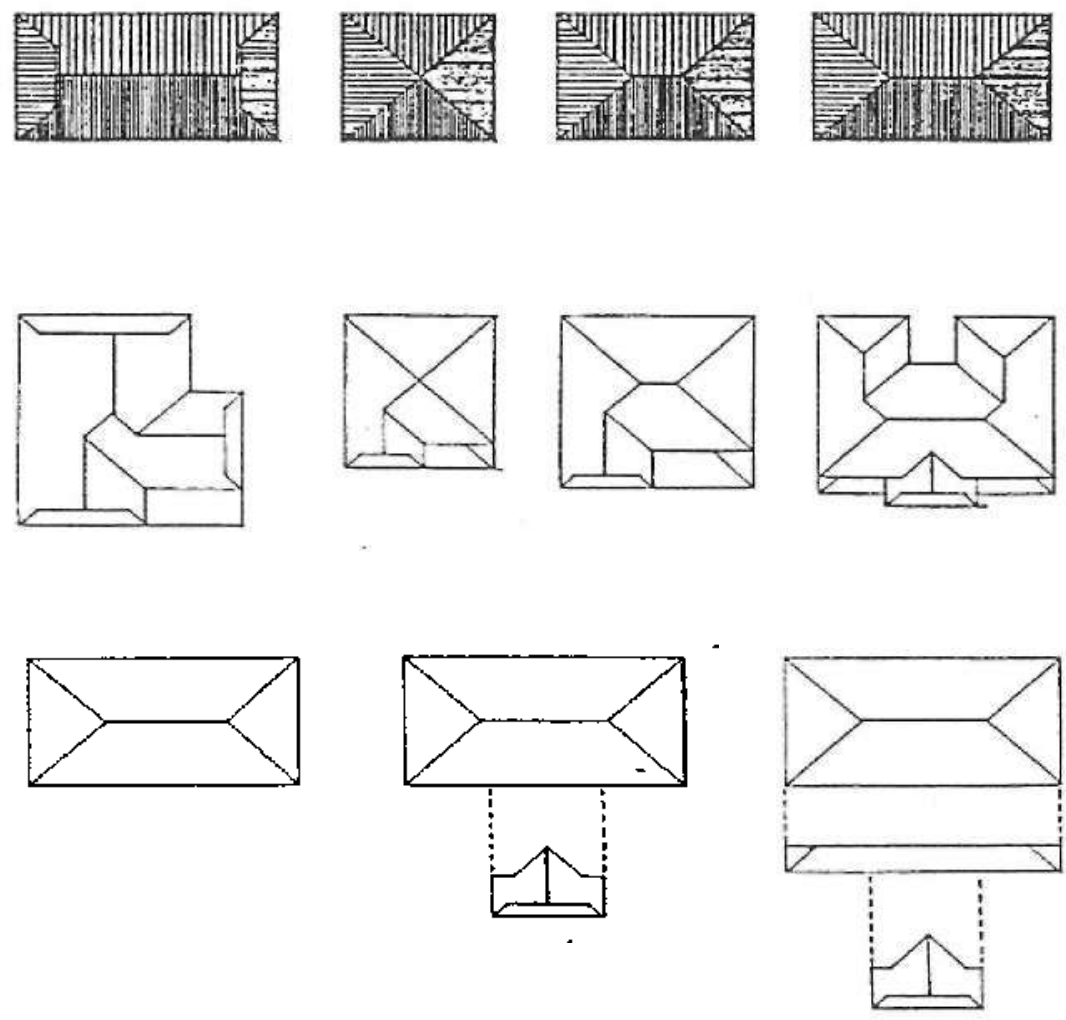

FIGURA 6 - Coberturas/Tipos
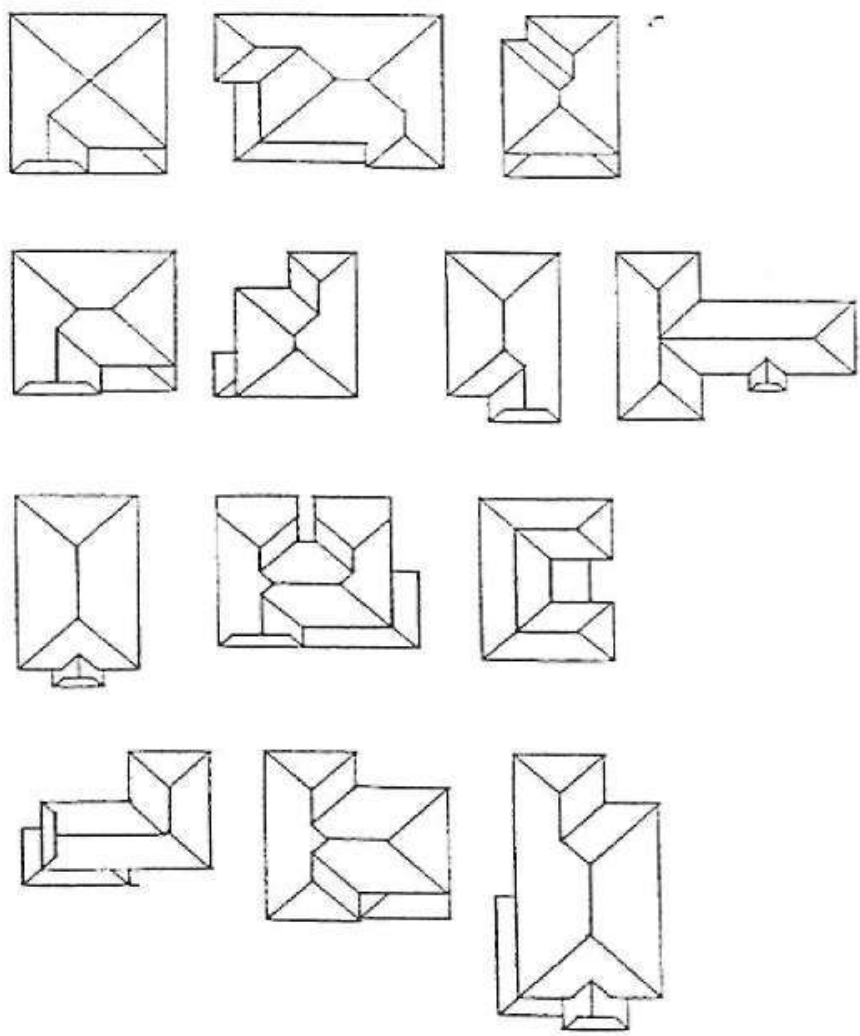

FIGURA 7 - Articulação de Coberturas 
$\mathrm{Na}$ planta padrão é constante o seu desenvolvimento em torno de um espaço central dando acesso direto aos aposentos, ausência de corredores.

Outro elemento é a varanda e o guenkan (hall), isoladamente ou acoplados: varanda como espaço de uso e o guenkan como espaço simbólico. Resultado muitas vezes da melhor adequação do programa ao sítio (Fig. 8) .

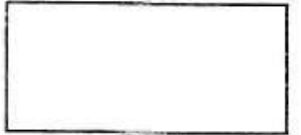

Fing
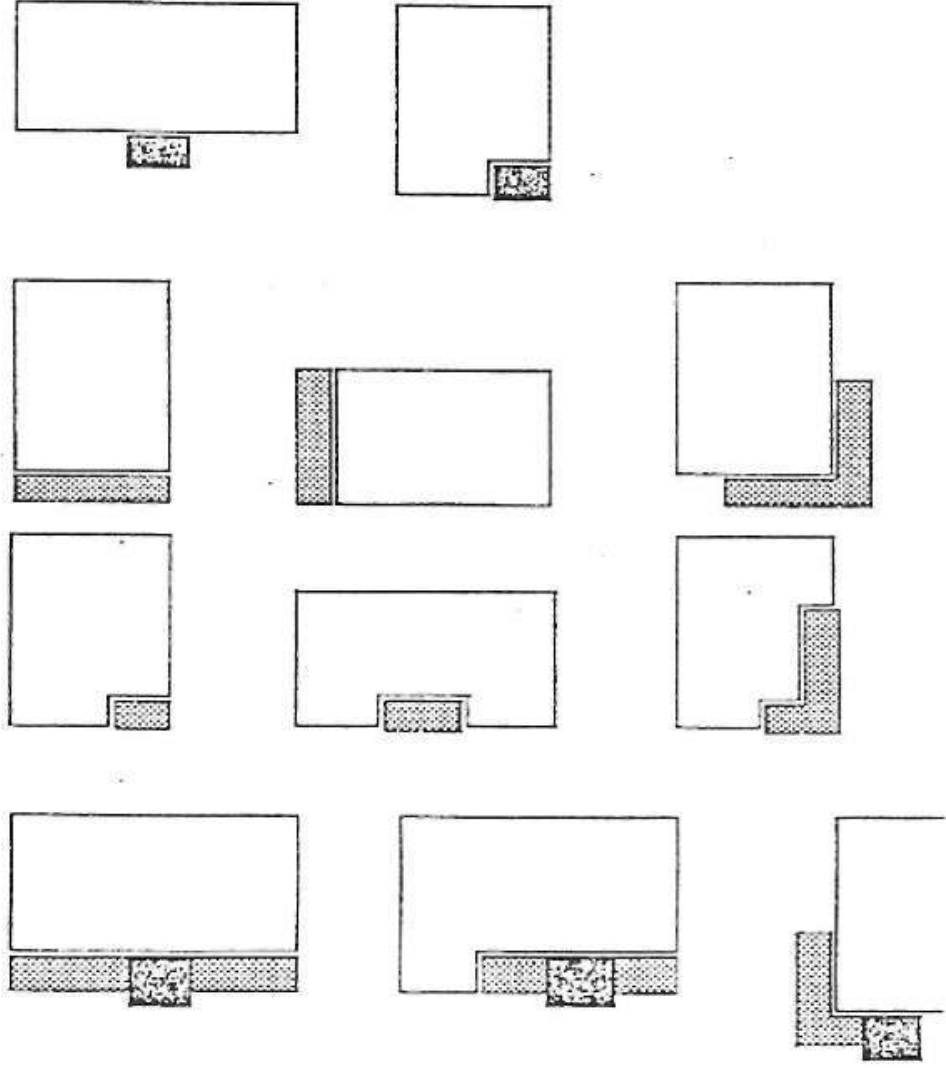

FIGURA 8 - Guenkan e Varanda/Tipos

O sistema construtivo em constante transformação procurou se adaptar aos programas emergentes. A evolução dos tipos padrão inicial em madeira resulta em construções em alvenaria com permanência dos elementos de caracterização, sempre mantendo as unidades isoladas no lote.

\section{PAISAGEM DE CONJUNTO}

Situada em sítio com topografia acidentada e tensionada, Assai mantém harmonia no seu conjunto tradicional. Existe homogeneidade em relação à adequação, solução, material, cor e ritmo; e riqueza nos detalhes resultando em qualidade significativa, como no exemplo da Rua Petrópolis (Fig.9).

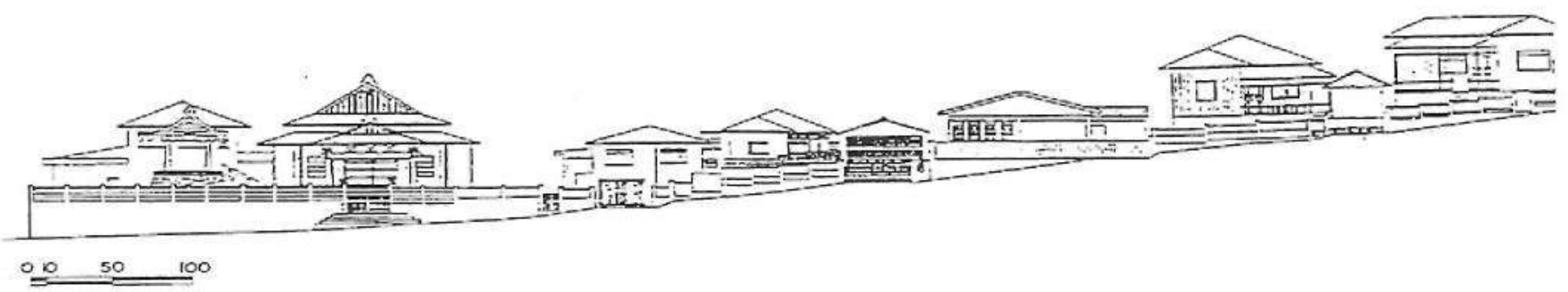

FIGURA 9 - Fachadas Conjunto - Rua Petrópolis 
O projeto em desenvolvimento procura privilegiar a questão de conjuntos existentes e emergentes, e não ao virtuosismo isolado das construções.

As casas inventariadas servem como referências básicas ao projeto do conjunto (Fig.10).

Assim, muro, cor, telhado e vegetação constituem elementos possíveis a serem trabalhados para a estruturação da paisagem. A homogeneidade como qualidade urbana.

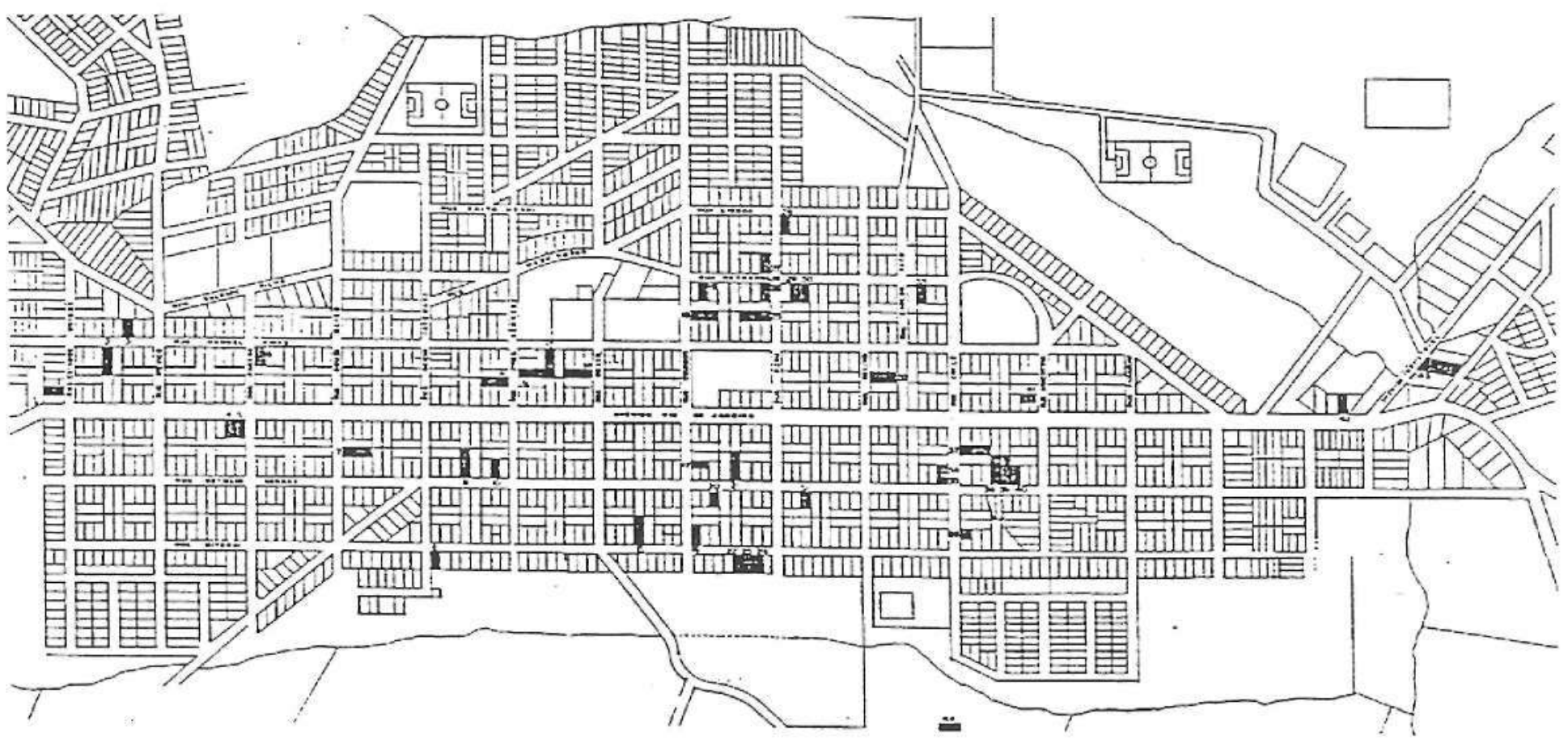

FIGURA 10 - Distribuição da Arquitetura Assaiense

\section{NOVA TRADIÇÃO}

Reformas e novas construções têm surgido nem sempre de acordo com o caráter local e regional, argumento para possível regulamentação. A organização de um guia de design delinea a possibilidade de desenvolvimento de novos projetos, resgatando aspectos da arquitetura tradicional e outros aspectos emergentes.

\section{DIRETRIZES DE RECUPERAÇÃO}

A estratégia propõe a ação em três níveis básicos, reforçando o potencial edificado: ponto, axis e setores.
O processo inicia-se através da recuperação de elementos pontuais, edificações isoladas, recuperação de axis e finaliza reforçando os setores através da sua recomposição temática.

Um roteiro histórico-arquitetônico-paisagístico integra a proposta.

\section{DUAS VERTENTES}

A manutenção do acervo tradicional e a criação de uma nova tradição é vertente do projeto relativo ao início do processo.

A lei 454/93 estabelece incentivos à nova 
arquitetura (não necessariamente de madeira) com traços (não cópia) da arquitetura tradicional assaiense.

A lei 498/94 estabelece benefícios e incentivos fiscais à preservação de edificações e conjuntos de valor histórico, cultural e arquitetônico.

Ambas contemplam o proprietário com isenção de IPU-Imposto Predial Urbano, que varia com o grau de envolvimento ao plano global. Em 1995 várias residências foram isentadas iniciando-se a efetivação do projeto.

Outra vertente refere-se aos infills criteriosos e criação de setores coesos e homogêneos através de diretrizes de qualificação.

Uma comissão constituída por membros da comunidade vem se reunindo mensalmente, definindo estratégias de desenvolvimento do processo.

\section{REQUALIFICAÇÃO URBANA}

Um conjunto urbano com atratividade deve permitir a apreensão de sua estrutura e seus fragmentos de maneira ordenada, a recuperação do caráter e da identidade.

O projeto de Requalificação Urbana de Assaí prevê o reconhecimento do acervo, criação de uma nova tradição, diretrizes de recuperação de conjunto, legislação de apoio visando a sua estruturação e intervenções nos espaços públicos abertos. Exposições e workshops, visando a conscientização da comunidade implementam o projeto.

Uma cidade para ser vista e ser vivida.

\section{NOTA}

O Projeto Requalificação Urbana vem sendo desenvolvido por HUMBERTO YAMAKI \& MORPHOLÓGICA ARQUITETOS, Londrina-PR: Humberto Yamaki-Supervisão Geral, Milena KanashiroCoordenação, Fausto Anami-Arquiteto, Estagiários DAUUEL-Roberto Magalhães, Juliana Trujillo. Na Fase Preliminar: Alessandra Aguilera, Carla Umezu, Deise Uehara, Giovanna Nakamura, Rinaldo Takahashi.

\section{AGRADECIMENTOS}

Prefeito de Assaí: Dr. Yoshinori Fucuda, Presidente da Câmara Municipal: Dr. Sanyo Sassakí, ex-Presidente da Câmara Municipal: Dr. Lauro Tanno, Sr. Jurio Kogishi/ LACA-Liga das Associações Culturais de Assaí, Sr. Cláudio Sato/SAMA-Sociedade Amigos de Assaí, Sr. Shiro Suzuki, Proprietários e Comunidade Assaiense.

YAMAKI, H.; KANASHIRO, M.; ANAMI, F. The process of urban re-qualification in Assaí-PR. Semina: Ci.

Exatas/Tecnológicas, Londrina, v. 16, n. 4, p. 581-590, Dec. 1995.

ABSTRACT: Assaí located in the North region of Paraná State was founded by BRATAC in 1932 to settle rnainly Japanese immigrants. The urban area maintained the morphological characteristics of a plan designed by Japanese Colonization Companies, having the school as a core. in 1993 a new process called URBAN REQUALIFICATION was started to re-structure the town, with particular emphasis on the recovery of the character and identity. The morphologicaltype analysis of traditional dwellings dellineated a group of significam buildings stock. This fact reaffirms the need for a continuity, an attractivity potential. As a result of the fragility of those wooden houses and disappearance of traditional construction techniques, the local architecture has sistematically been eroded. An adequate legistation and the creation of a new tradition are necessary to reinforce the importance of regionality. The action to encourage the community to give value to the experience of the place is implied in order to create and defend an architectural landscape.

KEY-WORDS: Urban requalification; morphology; collection inventory.

\section{REFERÊNCIAS BIBLIOGRÁFICAS}

COUNTY COUNCLL OF ESSEX. A Design Guide for Residential Areas. Essex, 1974.

MOUDON, A.V. Buitt for Change, Cambridge, MIT Press, 1986.

PARCHEN, R., Coord. LAPA, Um Passeio pela Memória. Coordenadoria do Patrimônio Cultural, PR, Curitiba,
1993.

YAMAKI, H. New Towns in Brazil: a Morpho-Genealogical Approach, Tokyo, Daiichi Juuken, 1994.

YAMAKI, H. et allìi. Requalificação Uかana, a experiência de Assaí. IV Congresso Latino Americano Sóbre Cultura Arquitetónica e Urbanistica. Curitiba, 1994. 